\title{
The Social Media Usage and its Impact on the Innovative Behavior: The Mediator Role of Information Technology: A Field Study in the Information and Communication Technology Organizations in Jordan
}

\author{
Khalid Mahmmod Ahmad Mansour ${ }^{1}$ \& Fayez Jomah Saleh Al-Najjar ${ }^{2}$ \\ ${ }^{1}$ Typical Network (mobily.ws), Business Development Director, Amman, Jordan \\ ${ }^{2}$ The World Islamic Science and Education University (WISE), Management Department, Amman, Jordan \\ Correspondence: Khalid Mahmoud Ahmad Mansour, Typical Network (mobily.ws), Business Development \\ Director, Amman, Jordan. E-mail: khalid_shaheen3@hotmail.com
}

Received: September 2, 2018

doi:10.5539/ijbm.v13n11p46
Accepted: September 30, 2018

Online Published: October 12, 2018

\begin{abstract}
This study aimed to shed the light on the role of Social Media usage in the innovative behavior through the recent information technology (IT) in the organizations specialized in the information and communication technology (ICT) field. The study population consisted of the ICT organizations operating in Jordan as affiliated with the Information and Communication Technology Association (INTAJ) amounting to 161 organization. The analysis unit consisted of the managers in the top and middle level. The study relied on the simple random sample; and it reached a number of conclusions the most important of which is that the perceptions by respondents of the independent variable Social Media Usage were medium; and the same applies to all its dimensions.

The dependent variable Innovative Behavior was also medium, as well as all its dimensions. As for the mediator variable IT, the respondents' perceptions were high, along with all its dimensions. The study indicated that there is a statistically significant impact for the Social Media usage with its component on the innovative behavior. Also, it was found that a statistically significant impact for the Social Media usage with its component on the innovative behavior through the IT in the organizations operating in the ICT field in Jordan. These conclusions indicated that there is an opportunity for the ICT organizations to promote its innovative behavior through the Social Media usage. Based on the reached conclusions, the study concluded a set of recommendations the most important of which is that the awareness should be increased with respect to the capacities that are available due to the use of the Social Media as well as the advantages that can be utilized by the ICT organizations in Jordan through this use; the organization should well utilize the Social Media usage especially the Groups and Sharing by taking the necessary decision that lead to the activation of the Social Media role in the various phases of the innovative behavior; and the need for the organizations to direct the use of Social Media through the dissemination of a culture of innovation based on the use of Social Media.
\end{abstract}

Keywords: social media, innovative behavior, information technology

\section{Introduction}

Many business organizations realized recently that the Social Media can be exploited to achieve its strategic goals, achieve a competitive advantage that help these organizations in reaching their clients, develop their operations and products, and create new ideas that enable them to survive in the markets and achieve the desired development; these are basic essential requirements for these organizations, especially in light of global competition taking place in market nowadays.

The importance of this study emanates from the remarkable appetite of business organizations to adopt these technologies in an effort to take advantage of the magnificent use of Social Media by internet users. Based on a report by the (Pew Research Center, n.d.), the vast majority of internet users use the Social Media. (eMarkter, n.d.) announced that the number of Social Media users in Jordan will increase by $22.6 \%$ in 2014 . Therefore, there is a need to study this phenomenon and analyze its dimensions, and study its effect on the innovative behavior. 
This study aims to comprehend the reality of using Social Media by the ICT organizations in Jordan, and how to utilize and interact with it in various forms, in order to reach new ideas and opportunities that enable these organizations from developing their own business, products, and internal operations; therefore, this research is based on studying the impact of the Social Media usage in the innovative behavior for the organizations in order to help them to take necessary decisions to benefit from such technologies.

Given the important role played by the recent IT in its various components in providing the capabilities necessary to connect the Social Media platforms and obtain information. Thus, this study chose the information technology as a mediator variable by which the Social Media usage impact the innovative behavior in the ICT organizations in Jordan.

\subsection{Study Objectives}

The study aims to achieve the following objectives:

- Identify the Social Media usage by organizations operating in the ICT field in Jordan.

- Study the role of Social Media usage in the innovative behavior in organizations operating in the ICT field in Jordan

- Study the role of Social Media usage in the innovative behavior through the mediator role of IT in the organizations operating in the ICT field in Jordan.

\subsection{Study Problem}

The study problem represented in the need to examine the impact of using Social Media, including its communication technologies and the huge amount of the user generated content, in the innovative behavior, and to inspect in-depth the phenomenon of using these rapidly developing technologies among ICT organizations in Jordan.

The study problem can be best represented by the following questions:

- What are the main Social Media usage and the level of using such media in the ICT organizations in Jordan.

- What is the role of Social Media usage dimensions in the innovative behavior through the information technology in the ICT organizations in Jordan.

\subsection{Study Hypotheses}

$\mathrm{H}_{\mathrm{o}} 1$ : There is no statistically significant impact at the significance level of $(\mathrm{P} \leq 0.05)$ for the Social Media usage with its components on the innovative behavior for the ICT organizations in Jordan.

$\mathrm{H}_{\mathrm{o}}$ 2: There is no statistically significant indirect impact at the significance level of $(\mathrm{P} \leq 0.05)$ for the Social Media usage with its components on the innovative behavior through information technology for the ICT organizations in Jordan. 


\subsection{Study Model}

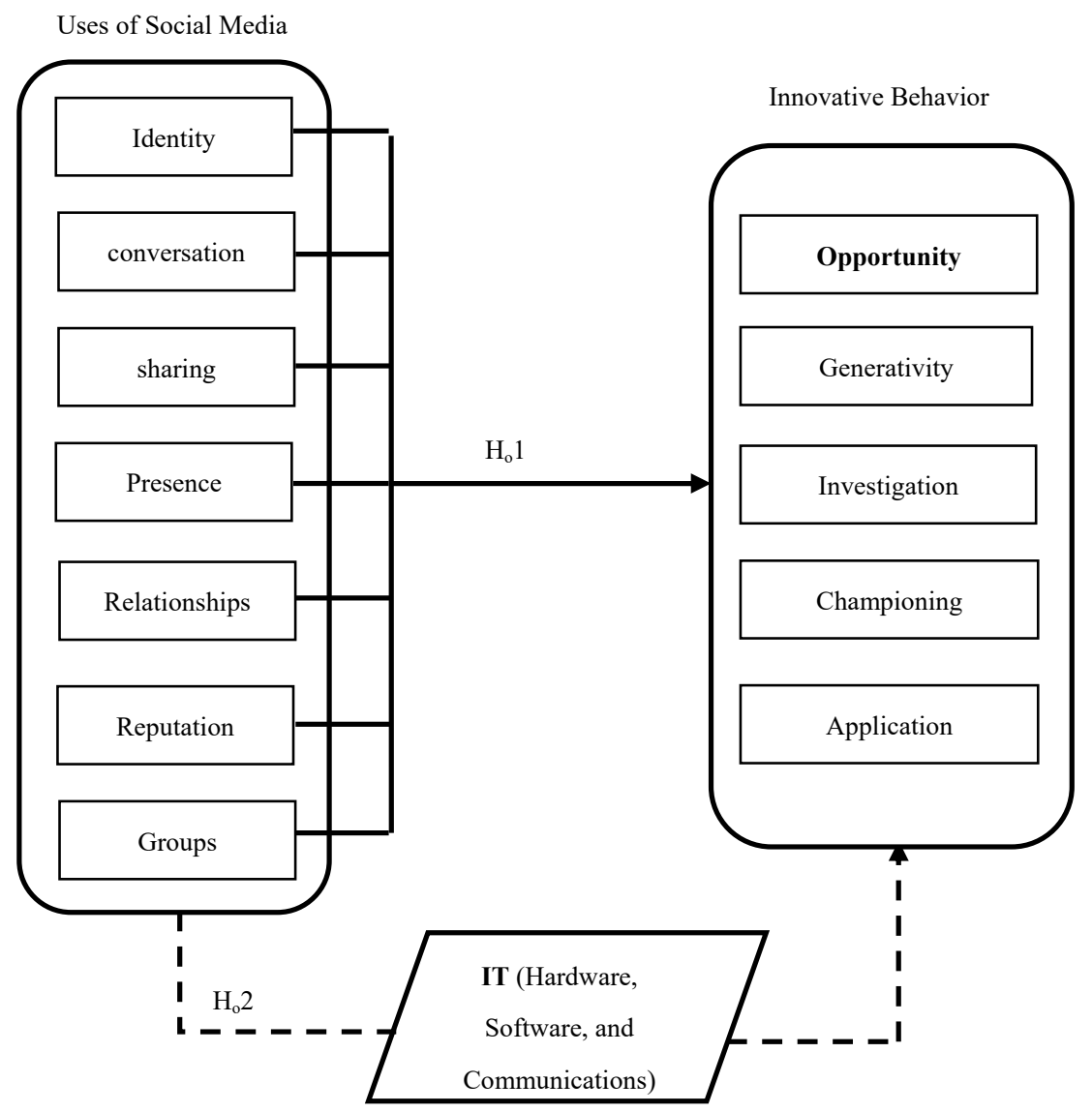

Figure 1. Study model

Source: the following sources were consulted with respect to the components of the independent variable: (Kietzmann, Hermkens, McCarthy \& Silvestre, 2011), (Kleysen \& Street, 2001; Kanter, 1988) was consulted for the components of dependent variable, and (Daley, 2005, 430) was consulted for the dimensions of the mediator variable.

\section{Literature Review}

The study of Trainor, Andzulis, Rapp and Agnihotri (2014) used Conversations, Sharing, Relationships and Groups as factors to measure the Social Media. The study was conducted on the top management level for 1200 organizations within a group of sectors in the United States of America. The study concluded that the organizations which utilized the Social Media technologies along with the management systems that focus on customers succeeded in developing the abilities of social customer relationship management (Social CRM).

The model developed by Roblek, Pejic Bach, Mesko and Bertoncelj (2013) represented the Social Media and their operations as a system that enable organizations to acquire knowledge; the study showed that the Social Media enable organizations in knowledge management and use the external knowledge within its internal operations through sharing and exchanging knowledge with the external environment and by use of information based on the customer's behavior on the internet which would help the organization to take effective decisions that help it to introduce organizational changes and adapt to the changing external environment. The study also showed that the application of Social Media has an effect on increasing the added-value.

Smits and Mogos (2013) conducted a case study on the German-based company SponsorPay. The study concluded that the highest impact of using the Web 2.0 was on the cooperation and communication operations, while the least impact was on the innovation processes; and the personnel specialized in IT showed greater impact than those specialized in business. The study concluded that the Social Media usage leads to the improvement of business capacities.

The study of Antes and Schuelke (2011) stressed the role of Social Media in the provisions of unprecedented methods and volumes of communications which would help people participating in the innovative and creative 
process to communicate and coordinate with each other in a better way. The study inferred that if the Social Media was applied in an appropriate manner among an organization's personnel, it can be utilized for the development of capacities of innovative leadership among the employees of that organization. Also, the study showed that the Social Media can be used in the final stages of creative efforts related to innovation.

Lina (2011) study was conducted on a number of companies working in the field of IT in Taiwan. The study concluded that the IT and virtual organization are being used as a beneficial tool by the HR managers for the training and education of employees, and then to transform employees' creativeness into an organizational innovation. It also concluded that the IT technologies have direct and indirect impact over organizational innovation.

The study of Karkkainen, Jussila and Vaisanen (2010) aimed to investigate the capacities of Social Media and the utilization of such technologies in the creativity, especially from the point of view of the business to business (B2B) Finnish organizations. The study concluded that there is a gap between what Social Media can provide of capacities and what is already utilized .

Lindermann, Valcarcel, Schaarschmidt and Kortzfleisch (2009) investigated whether there is a possibility for using the web 2.0 applications to promote the sharing of innovative and creative ideas. The study was conducted on "WirtschaftsForum Neuwied e.V" network which is a network related to the small and medium companies in Germany. The study concluded that the personnel's participation in exchanging the innovative ideas by using the web 2.0 applications is based on factors like trust, security of sensitive data, and balance between effort and economic advantage.

\section{Theoretical Framework}

\subsection{Innovative Behavior}

Innovation helps business organizations to increase their capacity to compete; therefore, business organizations have to continue to innovate in order to survive in the markets and to achieve a competitive advantage in the market (Simon, Elango, Houghton \& Savelli, 2002). Innovation is a multi-phased process whereby organizations can transfer ideas into products, services or new operations that help the organization to advance, compete, and be distinguished in terms of success within the market (Baregheh, Rowley \& Sambrook, 2009). While the innovative behavior is the deliberate addition by an employee of new ideas, products, operations, or procedures to his/her job, unit, or organization (West \& Farr, 1989). The innovative behavior was defined as: multi-phased process by which an individual recognizes a problem and then generates new ideas and solutions for it (either genuine or adopted ideas), promote and support these ideas, and then produces an applicable model that can be utilized by the organization or part of it (Carmeli, Meitar \& Weisberg, 2006).

\subsubsection{Phases of Innovative Behavior}

\subsubsection{Opportunity Exploration}

The opportunity exploration phase is the first step by which an innovator starts the innovation process. At this phase, the innovator determines the goal to be achieved; he/she starts first to search for the appropriate opportunity that satisfies specific needs, and then collects the necessary information about such opportunity in order to be better understood and clear enough. The opportunity exploration behavior according to the study of Kleysen and Street (2001) is defined as: "the intensified effort with the aim to find, investigate and understand innovation opportunities. The resources which an innovator can consult and search for an opportunity are several. Barringer and Ireland (2012, 70-80) indicated three main resources, namely: Observing Trends, Problem Solving, and Market Gap.

\subsubsection{Generativity}

The generativity phase starts after finding the appropriate opportunity and completing the collection of necessary information about it. This phase is described as the phase of interest in the creation and direction of new generation of beneficial changes to the organization (Kleysen \& Street 2001). Opportunity differs from idea in that an idea is mere thought, impression, or opinion, and it is not necessary that such idea meets the standards of available opportunity (Barringer \& Ireland, 2012,70). Some researchers believe that this phase is the one where creativity takes place (Scarborough, 2011, 51; O'Sullivan \& Dooley, 2009, 7; Amabile, 1996; Cook, 2000, 6). The study of Kleysen and Street (2001) indicated three sub-behaviors within the behavior of generativity in the course of researching the innovation behaviors; these sub-behaviors include: 1) Generating ideas and solutions for opportunities, 2) Generating representations and categories of opportunities, 3) Generating associations and combinations of ideas and information. 


\subsubsection{Investigation}

Investigation is one of the necessary phases of innovation process. At this phase, the reliability and feasibility of ideas to add value is ensured, and the ideas ability to use the opportunity and meet the purposes is ascertained. O'Sullivan and Dooley $(2009,63)$ indicated that in this phase the ideas generated in the previous phase are formulated and concretized so that their performance on the ground can be tested through the testing, designing, experimenting, examining, market analyzing, and prototyping. This phase involves the following sub behaviors: Formulating Creative Ideas, Experimenting Creative Ideas and Evaluating Creative Ideas (Kleysen \& Street, 2001).

\subsubsection{Championing}

Howell and Higgins (1990) defined the championing behavior as: "The acts of support provided by an individual to the creative ideas in order to be successfully implemented in reality". The individual who supports and advocates creative ideas is called (Champion); he/she is the person who can cause creative ideas to proceed towards the implementation and transformation into a successful innovation by overcoming all obstacles which may be faced. The champion provides support without official assignment (Shane, 1994).The championing behavior involves four sub-behaviors, namely: Mobilizing Resources, Persuading and influencing, Pushing and Negotiation, and Challenging and Risk Taking (Kleysen \& Street, 2001).

\subsubsection{Application}

Innovation is generated at the last phase of innovative behavior; it is the application phase where the creative idea is put to implementation in reality and reaping the rewards of the creative idea starts with the satisfaction of needs and utilization of opportunities, along with the continued development and improvement on such idea. The researchers agree with (O'Sullivan \& Dooley, 2009, 7; Zimmerer \& Scarborough, 2005, 35; Hatten, 2011, 12) and (Khairullah, 2009, 10) that the application phase is the phase which differentiates between creativeness and innovation. Innovation at this phase is subject to the direct testing by the customer; he/she is the one who will assess such innovation at this point. According to (Kleysen \& Street, 2001): the application phase includes the following behaviors: Implementation, Modifying, and Reutilizing.

The researchers agree with the conclusions reached by O'Sullivan and Dooley $(2009,63-64)$ with respect to the importance of the Feedback, and that an organization has to learn from its experience in this innovation through studying and examining the phases which innovation passes, so that it is able to avoid committing the same mistakes upon development of another innovation. Moreover, the information obtained by an organization may allow it to explore new opportunities that open the door for the generation of creative ideas and thus develop a new innovation.

\subsection{Social Media}

The Social Media dominated a majority of Internet uses in the world. In 2013, the proportion of Social Media users compared to the internet users in general amounted to $68 \%$; it was expected to surpass $70 \%$ by the end of 2014 according to a study conducted by eMarketer, (n.d.). A report published by Pew Research Center indicated that the vast majority of internet users in Mexico, Brazil, Tunisia, Jordan, Egypt, Turkey, Russia and India are using social networking sites (Pew Research Center, n.d.). The report predicted that the number of Social Media users in Egypt and Jordan will increase by $22.6 \%$ in 2014.

\subsubsection{Social Media Concept}

The study of Evans (2012) defined the Social Media as an arena for the sharing of ideas, experiences and information in order to obtain a better and more enlightened choice. While the study of El Ouirdi, El Ouirdi, Segers and Henderickx (2014) defined the Social Media as a web and mobile-based platforms that are built on the Web 2.0 which enable the users of various levels to share and make tags (geo-tags) of a user-generated content, and to cooperate with other users to build networks and communities, along with the possibility to reach a large segment of audience.

The researchers indicated that the Social Media can be defined based on its type of usage and Based on Kietzmann, Hermkens, McCarthy and Silvestre (2011) model as: a set of technologies which enable users to save their personal data, create relationships, share information, create groups, conversation/chat, determine the online status, and interact with each other. 


\subsubsection{Social Media Functional Blocks}

Kietzmann et al. (2011) provided a framework that shows the functional features of the Social Media. they indicated seven functional features which he called the "Functional Blocks" for Social Media, which were adopted in this research, and they are:

\subsubsection{Identity}

The identity includes a group of characteristics through which a user is identified and distinguished. A user may be an individual or organization. User's identity focuses on the information related to user; most of Social Media platforms require a user to enter their personal data in order to be saved as a user profile (Camp, 2004; Jain, Ross $\&$ Prabhakar, 2004). The classes of information which distinguish a user from other are called (identifiers) when they are used to identify a user (Hansen, Berlich, Camenisch, Claub, Pfitzmann \& Waidner, 2004).

\subsubsection{Conversations}

A user starts a conversation by adding some content which causes another user to respond to it. concentration through Social Media takes place in an open and direct way that allows users to discuss, chat, and express opinion. Such conversation may take place between two users and there may be millions of users who see and interact with such conversation (Henderson \& Bowley, 2010).

\subsubsection{Sharing}

Through the sharing feature, users can receive, send, distribute or exchange content among each other on the Social Media. The shared content is considered as the social element that mediates the relationship between users; it is the very reason of their connection and meeting on the internet (Lee \& Ma, 2012). The study of Androutsopoulos (2014) indicated that sharing is a behavior which consists of three levels: the first level is Selection, which represents the moment in which a user takes the decision to share a content, the second is the Styling, which involves the words used by the user to describe the shared content, and the third level which is Negotiating: it refers to the actions taken by a user in publishing and distributing the content to users, which is followed by interactions by the users with whom such content is shared.

\subsubsection{Presence}

The presence of a user on the Social Media enables him/her to know the presence status of the other users and where they are; either in the virtual world or in the real world. In the case of virtual world, when user's status appears as "Available" this means that he/she is present in the virtual world; however, when the status appears as "Not Available" this means that he/she is not present in the virtual world. (Kietzmann et al., 2011).

\subsubsection{Relationships}

Relationships in Social Media refer to the manner in which users are connected to each other in the virtual society with the aim to socially interact and share content; these relationships may be formal and regulated as is the case in Facebook and Linkedin or informal and non-regulated as is the case in Twitter and Youtube where a user can go to another user and create a relationship without any previous link or prior personal knowledge of him/her (Kietzmann et al., 2011).

\subsubsection{Reputation}

The reputation in Social Media is the status of users in front of each other; it reflects the amount of trust of users among themselves (Edwards, Spence, Gentile, Edwards \& Edwards, 2013). The reputation does not only represent a user's own status, but rather the content offered by such user (Kailer, Mandl \& Schill, 2013).

The study of Kailer et al. (2013) referred to some standards related to reputation available on the Social Media platforms, such as the addition of positive or negative hint to the Reviews, Like a product, customer Ratings, customer Comments, Rating of comments by other customers, and Tag to a link of product page, and the reputation that is based on individuals which is an indication to the social status of individuals who carry our such (Rating) or (Like).

\subsubsection{Groups}

Groups in Social Media refer to communities which users can create or join through the platforms of Social Media. These communities may be main groups that are comprehensive and address a public affair, or subgroups that a are concerned with minor issues branched from the main group (Fulcher, 2014). There are two types of groups in the Social Media: the first type is those groups managed by the user him/herself, and the second type is those groups which user chooses to join (Kietzmann, Hermkens, McCarthy \& Silvestre, 2011; Kim, Jeong \& Lee, 2010). 


\subsubsection{Information Technology}

O'Leary and O'Leary $(2013,501)$ and Malaga $(2005,3)$ defined information technology as the set of information which includes ICT technologies especially the internet technology. While Yadav $(2006,2)$ indicated that the IT includes the acquisition, processing, storing and dissemination of information in various forms such as audio, photos, texts, number and videos through the computer and communications composition that is based on microelectronics. The IT elements are three, First, Hardware which includes the, input, output, processing, storage and communication equipment, Second Software: this is a set of instruction followed by the hardware in order to perform certain function; these instructions direct the hardware with respect to what to do and when and how to do it. Software are divided into system software and application software, third Communications: this means the transfer of information over long distances through electromagnetic signals, the IT based on the main dimensions (Hardwar, Software and Communications), but it expressed these dimensions in its new form. i.e. Tablets, mobile applications, 4G etc... (Daley, 2005, 42,195, 430).

\section{Study Methodology}

\subsection{Nature and Type of the Study}

This study is an applied study in terms of nature, and explanatory in terms of purpose as it works to discover the cause and effect relationship between variables.

\subsection{Study Population}

The study population consists of managers in the middle and top levels of management in the organizations operating in the ICT filed in Jordan; these organizations were selected from among business organizations affiliated with the Information and Communication Technology Association (INTAJ). This Association consists of 161 organizations operating in the ICT field, with 780 managers working in the middle and top levels of management.

\subsection{Study Sample}

The study adopted the simple random sample. A simple random sample was taken to represent the study population. The sample consisted of 260 managers based on (Najjar, Najjar \& Alzoubi, 2017, 109). The Study questionnaire was sent as a link through emails and Social Media platforms to the study sample, and 221 valid questionnaires were retrieved during the period prescribed for the sample to fill out the questionnaire.

\section{4 Unit Analysis}

The analysis unit consists of managers working in the middle and top levels of management in the organizations operating in the ICT filed in Jordan affiliated with Information and Communication Technology Association (INTAJ).

\subsection{Study Tool (Questionnaire)}

Questionnaire was used as a tool for this study to collect the initial information. The questionnaire was developed based on a number of previous studies; it included demographic and occupational questions in addition to 72 questions involving the study variables (including the Social Media usage, innovative behavior, and information technology). The questionnaire consisted of the following parts:

1. Demographic and employment information, which includes personal and occupational information (age, educational level, specialty, number of years of experience, gender, managerial level, specialty of the organization, number of staff of the organization, age of the organization, nationality of the organization, and the targeted markets by the organization).

2. This part aims to measure the independent variable; it includes the Social Media in its dimensions including: Identity, Conversations, Sharing, Presence, Relationships, Reputation, and Groups. The following references were consulted in order to prepare this part of the questionnaire: (Kietzmann et al., 2011; Kim et al., 2010; Hansen, Shneiderman \& Smith, 2011, 17; Frith, 2014; Gladwell, 2010; Kailer et al., 2013; Androutsopoulos, 2014). 35 paragraphs were contained in this part; five paragraphs for each of the above dimensions.

3. This aims to measure the innovative behavior represented by: opportunity exploration, generativity, investigation, championing, and application. The following references were consulted to prepare this part of the questionnaire: (Kleysen \& Street, 2001; Kanter, 1988). 25 paragraphs were used in this part; five paragraphs for each of the above dimensions. 
4. This part measures the IT dimensions including: hardware, software, and communications. The following references were consulted to prepare this part of the questionnaire (Daley, 2005, 42, 430). 12 paragraphs were used in this part; 4 paragraphs for each of the above dimensions.

\subsubsection{Validity of the Study Tool}

The questionnaire was refereed by 29 professors and associate professors in Jordan Universities in order to ensure the feasibility of the questionnaire and its apparent creditability, and validity of the questionnaire content, the comments rendered by the referees were taken into consideration.. The questionnaire was built on Lime Survey web application and distributed electronically through email and Social Media platforms to the study sample;

\subsubsection{Reliability of the Study Tool}

The Internal consistency coefficient (Cronbach Alpha coefficient) was applied to the study variables and the study tool in general, in order to determine the degree of internal consistency of the answers. The values of Cronbach Alpha coefficient for the dimensions of the independent variable (Social Media usage) ranged between $0.710-0.846$ and this is an indicator to the consistency between the paragraphs of the study tool with respect to this variable.

The values of Cronbach Alpha coefficient for the dimension of the independent variable (innovative behavior) also rendered a positive indicator to the paragraphs of the study tool with respect to this variable; it ranged between $0.906-0.938$. Also, the same applies to the intermediate variable (IT), the values of Cronbach Alpha coefficient ranged between $0.728-0.866$; this is an indicator on the consistency of the study tool's paragraphs with respect to this variable.

Based on the above results of the internal consistency coefficient, it is evidenced that the paragraphs of the study tool are consistent and stable in general where the alpha value was (0.963); therefore, this confirms that there is a possibility to rely on this tool to conduct the statistical analysis for this study (Sekaran \& Bougie, 2010, 290).

\subsection{Study Model Fit of Statistical Methods Used}

The Appropriateness of the study data to the Linear Regression analysis tested through testing the variance inflation factor, multicollinearity test. Below are the results concluded:

\subsection{Variance Inflation Factor (VIF)}

The results of Variance Inflation Factor according to the table (1) show that the values of variance inflation factor for all independent sub variables were all above (1) and less than (10); and Tolerance value greater than (0.10). this indicates that there is no multicollinearity between the variables (Hair, Black, Babin \& Anderson, 2010, 198).

Table 1. Results of variance inflation factor (VIF) Test

\begin{tabular}{llll}
\hline Hypothesis & Model 1 & Variance Inflation Factor (VIF) & Tolerance \\
& Dimension of Independent Variable & & \\
\hline $\mathrm{H}_{0} 1$ & Identity & 1.716 & 0.583 \\
& Conversations & 2.071 & 0.483 \\
& Sharing & 2.184 & 0.458 \\
& Presence & 2.062 & 0.485 \\
& Relationships & 1.947 & 0.514 \\
& Reputation & 2.067 & 0.484 \\
& Groups & 1.730 & 0.578 \\
\hline
\end{tabular}

Dependent variable: Innovative Behavior.

\section{- Multicollinearity Test}

Pearson linearity correlation coefficients test was used in order to make sure there is no high linear correlation between the sub-variables in the dependent variable and the results were as in Table (2). 
Table 2. Correlation matrix for innovative behavior variable

\begin{tabular}{llllll}
\hline & $\begin{array}{l}\text { Opportunity } \\
\text { exploration }\end{array}$ & Generativity & Investigation & Championing & Application \\
\hline $\begin{array}{l}\text { Opportunity } \\
\text { exploration }\end{array}$ & 1 & 0.719 & 0.588 & 0.584 & 0.579 \\
Generativity & & 1 & 0.793 & 0.664 & 0.655 \\
Investigation & & 1 & 0.730 & 0.715 \\
Championing & & & 1 & 0.747 \\
Application & & & & 1 \\
\hline
\end{tabular}

(*) significant level at 0.05 .

According to table 2, all correlation values between the dimensions of the independent variable are less than 0.8 , which indicates that the sample is free of the high multiple linear correlation (Sekaran \& Bougie, 2010, 352; Gujarati, 2004, 359).

\subsection{Data Analysis and Hypothesis Testing}

\subsubsection{Characteristics of the Study Sample}

Tables 3, 4, 5 show the nature of the study sample in terms Age, Educational level, Specialization, Functional Class, Experience, and Gender in terms of frequency and percentages

Table 3. Characteristics of the study sample (Age, and Educational level)

\begin{tabular}{llllll}
\hline Age & Freq. & $\mathbf{\%}$ & Educational level & Freq. & $\mathbf{\%}$ \\
\hline Less than 25 year & 20 & 9.0 & Diploma & 15 & 6.8 \\
25- less than 35 year & 123 & 55.7 & BA & 167 & 75.5 \\
35- less than 45 year & 64 & 29.0 & MBA & 37 & 16.6 \\
45 year and above & 14 & 6.3 & Ph.D. & 2 & 0.9 \\
Total & $\mathbf{2 2 1}$ & $\mathbf{1 0 0 \%}$ & Total & $\mathbf{2 2 1}$ & $\mathbf{1 0 0 \%}$ \\
\hline
\end{tabular}

Table 4. Characteristics of the study sample (specialization, and functional class)

\begin{tabular}{llllll}
\hline Specialization & Freq. & $\mathbf{\%}$ & Functional Class & Freq. & \% \\
\hline Software & 110 & 49.8 & Project manager & 34 & 15.4 \\
Engineering & 41 & 18.5 & Director of Executive Management & 19 & 8.6 \\
Telecommunication & 5 & 2.3 & Head of Department & 72 & 32.6 \\
Design & 8 & 3.6 & Manager/Deputy Manager & 15 & 6.8 \\
B.A. & 22 & 10.0 & Senior & 63 & 28.5 \\
Other Specialization & 35 & 15.8 & CEO & 18 & 8.1 \\
Total & $\mathbf{2 2 1}$ & $\mathbf{1 0 0} \%$ & Total & $\mathbf{2 2 1}$ & $\mathbf{1 0 0 \%}$ \\
\hline
\end{tabular}

Table 5. Characteristics of the study sample (experience, and gender)

\begin{tabular}{llllll}
\hline Experience & Freq. & $\mathbf{\%}$ & Gender & Freq. & \% \\
\hline Less than 5 years & 48 & 21.7 & Male & 191 & 86.4 \\
5- less than 10 years & 84 & 38.0 & Female & 30 & 13.6 \\
10- less than 15 year & 53 & 24.0 & & & \\
15 year and above & 36 & 16.3 & & & \\
Total & $\mathbf{2 2 1}$ & $\mathbf{1 0 0 \%}$ & & $\mathbf{2 2 1}$ & $\mathbf{1 0 0 \%}$ \\
\hline
\end{tabular}

\subsection{Study Analysis Questions}

\subsubsection{The Relative Importance of Social Media Usage}

The average of the Social Media usage's dimensions in the organizations operating in the ICT field amounted to 2.776 as shown in the table 6 . This indicates that the perceptions of the members of the study sample about the independent variable as whole came at a medium level, and that all sub-dimensions also came at a medium level; 
this is contrary to the researchers' expectations, where this population of the study was chosen because it is close to the Social Media technologies and understands them better. Also, the table shows that the dimension of (Identity) ranked first with an average of 3.153 and standard deviation of 0.959 . As for the less use of Social Media by the members of the sample was the dimension (Presence) with an average of 2.563 and standard deviation of 0.933 .

Table 6. The average and standard deviation of the dimensions of social media use

\begin{tabular}{llllllll}
\hline Dimension & Identity & Sharing & Relationships & Conversation & Reputation & Groups & Presence \\
\hline Average & 3.153 & 3.043 & 2.857 & 2.619 & 2.611 & 2.586 & 2.563 \\
Std. & 0.959 & 0.913 & 0.821 & 0.910 & 0.789 & 0.938 & 0.933 \\
\hline
\end{tabular}

\subsubsection{Relative Importance of Innovative Behavior}

The average of the dimensions of innovative behavior in the organizations operating in the ICT field amounted to 3.45 as shown in the table 7. This indicates that the perceptions of the members of the study sample about the dependent variable as whole came at medium level, and that all sub-dimensions also came at a medium level. Also, the table shows that the dimension (opportunity exploration) ranked first with an average of 3.611 and standard deviation of 0.830 , while the dimension (Investigation) ranked last with an average of 3.329 and standard deviation of 0.949 .

Table 7. Average and standard deviation of the dimensions of innovative behavior

\begin{tabular}{llllll}
\hline & Opportunity exploration & Application & Generativity & Championing & Investigation \\
\hline Average & 3.611 & 3.508 & 3.407 & 3.405 & 3.329 \\
Std. & 0.830 & 0.940 & 0.922 & 0.958 & 0.949 \\
\hline
\end{tabular}

\subsubsection{Relative Importance of Information Technology}

The average of the IT dimensions in the organizations operating in the field of ICT amounted to 3.95. as shown in the table 8. This indicates that the perceptions of the members of the study sample about the mediator variable as whole came at a high level as expected, and that all sub-dimensions also came high as well. Also, the dimension (Communications) ranked first with an average of 4.224 and standard deviation of 0.851 , followed by the dimension of (Hardware) with an average of 3.828 and standard deviation of 0.892 . The dimension of (Software) ranked third with an average of 3.785 and standard deviation of 0.845 . These results are largely logical since the study population depends basically on the IT.

Table 8. Average and standard deviation of the dimensions of information technology

\begin{tabular}{lllll}
\hline & Hardware & Software & Communications & Common average \\
\hline Average & 3.828 & 3.785 & 4.224 & 3.946 \\
Std. & 0.892 & 0.845 & 0.851 & 0.751 \\
\hline
\end{tabular}

\subsection{Testing the Study Hypotheses}

\section{First Hypothesis}

Ho1: There is no statistically significant impact at the significance level of $(\mathrm{P} \leq 0.05)$ for the Social Media usage with its components (identity, conversation, sharing, presence, relationships, reputation, and groups) on the innovative behavior in the organizations operating in the ICT field in Jordan.

In order to test the first hypothesis, the standard multiple regression test was used and the results are shown in table 9 . 
Table 9. The results of testing the impact of social media usage in the innovative behavior

\begin{tabular}{|c|c|c|c|c|c|c|c|c|c|c|c|}
\hline \multirow[t]{2}{*}{ Dependent variable } & \multicolumn{2}{|c|}{ Model summary } & \multicolumn{3}{|c|}{ ANOVA } & \multicolumn{6}{|c|}{ Coefficient Table } \\
\hline & $\mathrm{R}$ & $\mathrm{R}^{2}$ & $\mathrm{~F}$ & Df & Sig F & Statement & $\mathrm{B}$ & $\mathrm{B}$ & standard error & $\mathrm{T}$ & Sig t \\
\hline \multirow[t]{7}{*}{ Innovative behavior } & $0.475^{\mathrm{a}}$ & 0.226 & 8.863 & 7 & 0.000 & Identity & $0.111-$ & $0.093-$ & 0.066 & $1.140-$ & 0.160 \\
\hline & & & & & & Conversation & $0.009-$ & $0.008-$ & 0.076 & $0.099-$ & 0.921 \\
\hline & & & & & & Sharing & 0.231 & 0.201 & 0.078 & 2.587 & 0.010 \\
\hline & & & & & & Presence & 0.125 & 0.107 & 0.074 & 1.440 & 0.151 \\
\hline & & & & & & Relationships & 0.024 & 0.023 & 0.082 & 0.286 & 0.775 \\
\hline & & & & & & Reputation & 0.102 & 0.103 & 0.088 & 1.172 & 0.342 \\
\hline & & & & & & Groups & 0.176 & 0.150 & 0.068 & 2.224 & 0.027 \\
\hline
\end{tabular}

a. Predictor: The variable Social Media Usage.

b. Dependent variable: Innovative Behavior.

The results of table 9 indicate that the correlation coefficient $(\mathrm{R}=0.475)$ refers to the positive relationship between the independent variables and dependent variable. Moreover, the impact of the independent variable (Social Media Usage) in all its dimensions on the dependent variable (Innovative Behavior) is statistically significant impact; the value of $F$ is (8.863) with a significance level of ( $\mathrm{sig}=0.000$ ) which is less than 0.05 ; it was found out $\left(\mathrm{R}^{2}=0.226\right)$ which means the significance of the regression.

As for the coefficient table, it showed that the sharing and groups coefficients are statistically significant, while the coefficients of identity, conversations, presence, relationships, reputation are not statistically significant; however, this confirms the significance of some coefficients.

Based on the above, we can confirm that the first null hypothesis is not accepted, and accept the alternative hypothesis which states: There is a statistically significant impact at the significance level of $(\mathrm{P} \leq 0.05)$ for the Social Media usage with its components on the innovative behavior at organizations operating in the ICT field in Jordan.

The study attributes this result to the fact that Social Media in itself are still new technology and that even the organizations working in the ICT field are still not fully aware of the possibilities and capabilities offered by these technologies.

\section{Second Hypothesis}

Ho 2: There is no statistically significant impact at the significance level of $(\mathrm{P} \leq 0.05)$ for the Social Media usage with its component on the innovative behavior through the IT in the organizations operating in the ICT field in Jordan.

Table 10 indicates that $\left(\mathrm{Chi}^{2}=42.09\right)$ at significance level $(\mathrm{sig} .=0.02)$ and $(\mathrm{GFI}=0.958),(\mathrm{CFI}=0.981)$, and the tow values come close to the right one. And the table also shows that (RAMSEA $=0.053)$ they are closer to zero. The above confirms the suitability model for testing.

Table 10. Results of model fit summary

GFI: Goodness of Fit Index

\begin{tabular}{lllllll}
\hline Statement & Chi $^{2}$ & Df & GFI & CFI & RAMSEA & Sig \\
\hline Innovative behavior & 42.09 & 26 & 0.958 & 0.981 & 0.053 & 0.02 \\
\hline
\end{tabular}

CFI: Comparative Fit Index

RAMSEA: Root Mean Square Error of Approximation

Table 11 Path Analysis indicates that Standardized direct effect of Social Media usage on the innovative behavior amounted to (0.261) and on IT amounted to (0.464), while it turns out the Standardized direct effect of IT on innovative behavior amounted to (0.494). all at a significance level (sig. $=0.001)$.

As turn out Standardized indirect effect of IT amounted to (0.229), where information technology was able to explain $(22.9 \%)$ of the impact Social Media usage on the innovative behavior in the organizations operating in the ICT field in Jordan. .

Finally the table showed that Standardized total effect for the Social Media usage with its component on the innovative behavior through the IT in the organizations operating in the ICT field in Jordan amounted to (0.94). 
Table 11. Results of the path analysis

\begin{tabular}{lllll}
\hline Paths & $\begin{array}{l}\text { Standardized } \\
\text { direct effect }\end{array}$ & Sig. & $\begin{array}{l}\text { Standardized } \\
\text { indirect effect }\end{array}$ & $\begin{array}{l}\text { Standardized } \\
\text { total effect }\end{array}$ \\
\hline Social Medial Usage $\triangleright$ Innovative Behavior & 0.261 & 0.00 & 0.229 & 0.490 \\
Social Medial usage $\triangleright$ IT & 0.464 & & & \\
IT $\triangleright$ Innovative Behavior & 0.494 & & & \\
\hline
\end{tabular}

Therefore, the $\mathrm{H}_{0} 2$ hypothesis do not accept, and we accept the alternative hypothesis which states:

There is a statistically significant impact at the significance level of $(\mathrm{P} \leq 0.05)$ for the Social Media usage with its component on the innovative behavior through the IT in the organizations operating in the ICT field in Jordan.

\section{Conclusions and Recommendations}

\subsection{Findings}

1. The study results indicated that the respondents' perceptions about the Social Media usage were in medium level. The same applies to all Social Media usage dimensions; the dimension of Identity ranked first, followed by Sharing, Relationship, Conversation, Reputation, Groups, and finally the Presence dimension. Despite the fact that this result came higher than the results of (Karkkainen, Jussila \& Vaisanen, 2010), where the level of Social Media usage in business organizations came at a low level, this study's result came below the researchers' expectations as for the IT field. The study ascribes this result to the fact that these technologies are still in the outset even in the organizations operating in the ICT field in Jordan.

2. The respondents' perceptions towards the Innovative Behavior came also in a medium level with all of its dimensions based on the results, where the dimension Opportunity Exploration came first, followed by Application, then Generativity, Championing and finally the Investigation dimension.

3. As expected for the nature of the study population the respondents' perceptions towards IT came in a high level along with all its sub-dimensions including the Communications dimension ranked first, then Hardware, and finally the Software dimension.

4. The results indicated that there is a statistically significant impact for Social Media Usage in its component on the Innovative Behavior, despite that the impact value was not high. These results were contrary to the researchers expectations. The study ascribes this result to the fact that even the organizations operating in the ICT field are still not fully aware of the advantages they can get from these technologies as they are one of the important sources of knowledge which can support organizations in promoting the innovation process at its various phases, and this consistent with the study of (Smits \& Mogos, 2013) in that there is low impact of Social Media on the innovation process.

5. A statistically significant impact was also found for Social Media usage in its component on IT, despite that the impact value was not high. The researchers ascribe this result to the fact that the Social Media usage causes users to secure the required recent hardware, software and communication technologies in order to stay connected to and interact with the Social Media platforms.

6. A statistically significant impact was also found for IT on innovative behavior in the organizations operating in the ICT field in Jordan

7. The results indicated that there is statistically significant impact for Social Media usage in its component on the Innovative Behavior through IT as a mediator variable.

This result is consistent with the following studies: the study of (Antes \& Schuelke, 2011) in that the Social Media has a positive impact on supporting the innovative and creative efforts, and the study of (Karkkainen, Jussila \& Janhonen, 2011) in that the Social Media has a positive impact in finding new opportunities, generate ideas and release products, and the study of (Lina, 2011) in that there is a direct and indirect impact for the IT on organizational innovation, and a direct impact on the performance of organizational innovation, and the study of (Benitez-Amado, Llorens-Montes \& Perez-Arostegui, 2010) in that there is an impact for the two types of IT resources in the development of internal leadership culture and that the Social Media has a positive impact in the development of innovation supportive culture. These results indicate that there is an impact of the Social Media usage in the innovative behavior through the IT. 


\subsection{Conclusions}

Based on the findings reached by the study, a set of conclusions can be summarized based on the interpretation and discussion of these conclusions, as follows:

1. The Social Media usage with its component impact on the innovative behavior of the organizations operating in the ICT field in Jordan, the conclusion suggests a possibility to utilize the Social Media usage in order to support innovation in such organizations.

2. Groups and Sharing in Social Media usage are a significant coefficient, the use of groups helps in reaching several resources for innovation in the internal and external environment of organization. Groups can also be used as means for generating innovative ideas in the organizations.

3. The use of "Sharing" in Social Media helps in the exchange of content and dissemination of such content among employees; thus, it can support the exploration of opportunities, generate ideas, and may be utilized in the championing and the application of innovative ideas in reality.

4. The organizations operating in the ICT field in Jordan are characterized by the fact that they have a medium level of using the Social Media; they are featured by having an innovative behavior that tends to be in high level.

\section{Recommendations}

Based on the study findings, this study recommends the following:

1. There is a need to increase awareness of the capabilities offered by the Social Media and the benefits which can be utilized by the organizations operating in the ICT field, by reading more reports and researches which highlight the capabilities offered by the Social Media for organizations; they have also to adopt strategies and policies that increase the effectiveness of using the Social Media by managers; to involve the managers who use the Social Media considerably in the development of such strategies and policies, and increase awareness of the advantages that may be obtained from Social Media and how to use it to achieve this end, and to hold training courses and use the material and moral incentives in this regard.

2. The organizations should activate the role of groups and sharing of Social Media usage in the innovative process, by allowing managers to access these technologies. As for groups, this can be achieved through the creation of special groups. Also, to creation public groups which can help in the exploration of new opportunities; to use these groups with the aim to generate ideas through brainstorming sessions in order to generate ideas and benefit from them in solving any emerging problems; to develop organizations business and promote innovative behavior among the organization. As for "Sharing", it can be promoted through encouraging employees to share the proper content among each other, and managing the way of what and how the content should be shared.

3. The ICT Organizations in Jordan should pay more attention to the hardware, software and communications which facilitate the use of Social Media, through increasing the knowledge of the available technologies and keep up to date with the new developments and advancements.

\section{References}

Amabile, T. (1996). Creativity and innovation in organizations. Boston, MA: Harvard Business School Publishing.

Androutsopoulos, J. (2014). Moments of sharing: Entextualization and linguistic repertoires in social networking. Journal of Pragmatics, 73, 4-18. https://doi.org/10.1016/j.pragma.2014.07.013

Antes, A. L., \& Schuelke, M. J. (2011). Leveraging technology to develop creative leadership capacity. Advances in Developing Human Resources, 13(3), 318-365. https://doi.org/10.1177/1523422311424710

Baregheh, A., Rowley, J., \& Sambrook, S. (2009). Towards a multidisciplinary definition of innovation. Management Decision, 47(8), 1323-1339. https://doi.org/10.1108/00251740910984578

Barringer, B. R., \& Ireland, R. D. (2012). Entrepreneurship successfully launching new ventures (4th ed.). England, Essex: Person Education limited.

Benitez-Amado, J., Llorens-Montes, F. J., \& Perez-Arostegui, M. N. (2010). Information technology-enabled intrapreneurship culture and firm performance. Industrial Management \& Data Systems, 110(4), 550-566.

Camp, L. J. (2004). Digital identity. Technology and Society Magazine, IEEE, 23(3), 34-41.

Carmeli, Abraham, Meitar, Ravit, \& Weisberg, Jacob (2006). Self-leadership skills and innovative behavior at work. International Journal of Manpower, 27(1), 75-90. https://doi.org/10.1108/01437720610652853

Cook, P. (2000). The creativity Advantage. Is your organization the leader of the pack. Uk: Gower, Al Dershort. 
Daley, B. (2005). Computers are your future 2005. New Jersey, NJ: Prentice-Hall, Inc.

Edwards, C., Spence, P. R., Gentile, C. J., Edwards, A., \& Edwards, A. (2013). How much Klout do you have... A test of system generated cues on source credibility. Computers in Human Behavior, 29(5), A12-A16. https://doi.org/10.1016/j.chb.2012.12.034

El Ouirdi, M., El Ouirdi, A., Segers, J., \& Henderickx, E. (2014). Social media conceptualization and taxonomy a Lasswellian framework. Journal of Creative Communications, 9(2), 107-126. https://doi.org/10.1177/0973258614528608

eMarketer (n.d). Retrieved 28/3/2014, from http://www.emarketer.com/Article/ Facebook-Usage-High-Egypt-Jordan/1010709.

Evans, D. (2012). Social media marketing: An hour a day. John Wiley \& Sons.

Frith, J. (2014). Communicating through location: The understood meaning of the Foursquare Check-in. Journal of Computer-Mediated Communication, 19(4), 890-905. https://doi.org/10.1111/jcc4.12087

Fulcher, C. L. (2014). Community commons: A unifying public good website for healthy, sustainable, and livable communities. National Civic Review, 103(1), 9-12. doi.org/10.1002/ncr.21165

Gladwell, M. (2010). Small change. The New Yorker, 4(2010), 42-49.

Gujarati, D. (2004). Basic econometrics (4th ed.). Washington, DC: McGraw-Hill.

Hair, J., Black, W., Babin, B., \& Anderson, R. (2010). Multivariate data analysis (7th ed.). Pearson Education.

Hansen, D., Shneiderman, B., \& Smith, M. A. (2011). Analyzing social media networks with NodeXL: Insights from a connected world. Morgan Kaufmann.

Hansen, M., Berlich, P., Camenisch, J., Claub, S., Pfitzmann, A., \& Waidner, M. (2004). Privacy-enhancing identity management. Information Security Technical Report, 9(1), 35-44. https://doi.org/10.1016/S1363-4127(04)00014-7

Hatten, T. S. (2011). Small business management: Entrepreneurship and beyond (5th ed.). USA, Natorp Boulevard Mason: Cengage Learning.

Henderson, A., \& Bowley, R. (2010). Authentic dialogue? The role of "friendship" in a social media recruitment $\begin{array}{lllll}\text { campaign. Journal of } & \text { Communication }\end{array}$ https://doi.org/10.1108/13632541011064517

Howell, J. M., \& Higgins, C. A. (1990). Champions of change: Identifying, understanding, and supporting champions of technological innovations. Organizational Dynamic, 19(1), 40-55. https://doi.org/10.1016/0090-2616(90)90047-S

Jain, A. K., Ross, A., \& Prabhakar, S. (2004). An introduction to biometric recognition. Circuits and Systems for Video Technology, IEEE Transactions, 14(1), 4-20. https://doi.org/10.1109/TCSVT.2003.818349

Kailer, D., Mandl, P., \& Schill, A. (2013). An empirical study on the usage of Social Media in German B2C-online stores. International Journal of Advanced Information Technology, 3(5), 1-14. https://doi.org/10.5121/ijait.2013.3501

Kanter, R. M. (1988). When a thousand of flowers bloom: Structural, collective, and social conditions for innovation in organizations. Research in Organizational Behavior, 10(July), 169-211. https://doi.org/10.1016/B978-0-7506-9749-1.50010-7

Karkkainen, H., Jussila, J., \& Janwhonen, J. (2011). Managing customer information and knowledge with social media in business- to business companies. I-KNOW, II Proceeding of the $11^{\text {th }}$ International Conference of Knowledge Management and Knowledge Technologies Article NO. 17.

Karkkainen, H., Jussila, J., \& Vaisanen, J. (2010). Social Media use and potential in business-to-business companies' innovation. MindTrek 10 Proceedings of the 14th International Academic MindTrek Conference: Envisioning Future Media Environments. 228-236.

Kietzmann, J. H., Hermkens, K., McCarthy, I. P., \& Silvestre, B. S. (2011). Social Media? Get serious! Understanding the functional building blocks of Social Media. Business Horizons, 54(3), 241-251. https://doi.org/10.1016/j.bushor.2011.01.005

Kim, W., Jeong, O. R., \& Lee, S. W. (2010). On social Web sites. Information Systems, 35(2), 215-236. https://doi.org/10.1016/j.is.2009.08.003 
Kleysen, R. F., \& Street, C. T. (2001). Toward a multi-dimensional measure of individual innovative behavior. Journal of Intellectual Capital, 2(3), 284-296. doi.org/10.1108/EUM0000000005660

Lee, C. S., \& Ma, L. (2012). News sharing in social media: The effect of gratifications and prior experience. Computers in Human Behavior, 28(2), 331-339. https://doi.org/10.1016/j.chb.2011.10.002

Lina, L. H. (2011). Electronic human resource management and organizational innovation: The roles of information technology and virtual organizational structure. The International Journal of Human Resource Management, 22(2), 235-257.

Lindermann, N., Valcárcel, S., Schaarschmidt, M., \& Kortzfleisch, H. V. (2009). SME 2.0: Roadmap towards Web 2.0-based open innovation in SME -Networks - A case study based research framework. IFIP Advances in Information and Communication Technology, 28-41.

Malaga, R. A. (2005). Information Systems Technology. New Jersey, NJ: Prentice-Hall, Inc.

Najjar, F. J., Najjar, N. J., \& Al-Zoubi, M. R. (2017). Scientific research methods: Applied perspective. Jordan, Amman: Dar Al-hamed for Publishing and Distribution.

O'Leary, T. J., \& O'Leary, L. I. (2013). Computing essentials 2013: making IT work for you. New York, NY: McGraw-Hill Companies, Inc.

O'Sullivan, D., \& Dooley, L. (2009). Applying innovation. California, CA: SAGE Publications Inc.

Pew Research Center. (n.d). $\quad$ Retrieved 28/3/2014, from http://www.pewglobal.org/2012/12/12/social-networking-popular-across-globe/.

Roblek, V., Pejic, B., Mirjana, M. M., \& Bertoncelj, A. (2013). The impact of social media to value added in knowledge-based industries. Kybernetes, 42(4), 554-568. https://doi.org/10.1108/K-01-2013-0014

Scarborough, N. M. (2011). Essentials of entrepreneurship and small business management (6th ed.). New Jersey, NJ: Prentice Hall.

Sekaran, U., \& Bougie, R. (2010). Research Method for Business, A Skill Building Approach (5th ed.). UK: West Sussex: John Wiley \& Sons Inc.

Shane, Scott A. (1994). Are champions different from non-champions? Journal of Business Venturing, 9(5), 397-421. https://doi.org/10.1016/0883-9026(94)90014-0

Simon, M., Elango, B., Houghton, S. M., \& Savelli, S. (2002). The successful product pioneer: Maintaining commitment while adapting to change. Journal of Small Business Management, 40(3) 187-203.

Smits, M., \& Mogos, S. (2013). The impact of social media on business performance. ECIS 2013 Completed Research.

Trainor, K., Andzulis, J., Rapp, A., \& Agnihotri, R. (2014). Social media technology usage and customer relationship performance: A capabilities-based examination of social CRM. Journal of Business Research, 67(6), 1201-1208. https://doi.org/10.1016/j.jbusres.2013.05.002

West, M. A., \& Farr, J. L. (1989). Innovation at work: Psychological perspectives. Social Behaviour, 4, 15-30.

Yadav, K. (2006). Components of Information Technology. India, Delhi: Standard Publishers Distributors.

Zimmerer, T. W., \& Scarborough, N. M. (2005). Essentials of entrepreneurship and small business management (4th ed.). New Jersey, NJ: Pearson Education.

\section{Copyrights}

Copyright for this article is retained by the author(s), with first publication rights granted to the journal.

This is an open-access article distributed under the terms and conditions of the Creative Commons Attribution license (http://creativecommons.org/licenses/by/4.0/). 